SHS Web of Conferences 12, 01023 (2014)

DOI: $10.1051 /$ shsconf $/ 20141201023$

(C) Owned by the authors, published by EDP Sciences, 2014

\title{
Langkawi Island, Social Aspect and the Carrying Capacity
}

\author{
Diana Mohamad ${ }^{1}$, Mastura Jaafar ${ }^{2}$, Azizan Marzuki ${ }^{3}$ \\ ${ }^{1,2,3}$ Sustainable Tourism Research Cluster (STRC), Universiti Sains Malaysia, Penang, Malaysia \\ ${ }^{1,2,3}$ School of Housing, Building and Planning, Universiti Sains Malaysia, Penang, Malaysia
}

\begin{abstract}
The aptitude to convince a range of preferences has facilitated the island tourism attractions to achieve international recognition and at present KILIM Geopark is enjoyed by a prominent percentage of individuals wide-reaching. Conventional knowledge has that the island attractions are operating on the limited immobile resources, of which, have raised the scholars' concerns over the carrying capacity issue. When analyzing carrying capacity, scholars have traditionally focused on the environmental part, hence, this working paper is motivated to convey onto the table issues relating to the social characteristics. This particular paper employed the self-administered questionnaire survey instrument which was structured to answer the two-fold objective specifically the tourists' satisfaction level with their tourism experience and knowledge gap in relation to improving the island tourism. Targeting the tourists with minimum age of 18 , this working paper collects information on the tourists' perception towards hospitality, facilities and safety issues. In addition, this working paper comes to scrutinize different results of demographic factors as compared to what have been documented by earlier studies. Besides, it is learned that 'safety issue' variable plays an important role when it comes to the following factors: tourist arrival, access to facilities and tourism experience.
\end{abstract}

\section{Introduction}

The island tourism is extensively experienced owing to the globe's profound economic expansion which in return, influences ones' financial stability. In parallel with the view of offering modernized and practical tourist destinations, islands and coasts of Malaysia have been developed. Located off the north-eastern coast of Peninsular Malaysia, KILIM Geopark is one of the Langkawi Island attractions which become one of the most visited tourism spots in Malaysia. Thus, the perfect landscape and beautiful natural resources of KILIM Geopark have attracted almost 300,000 visitors in year 2012 [1]. From the sight of sustainable tourism, developments are to encourage KILIM Geopark in sequence to take advantage of the economic benefits at the expense of minimum negative impacts. The rapid expansion of the tourism consumer population is interconnected with tourism socioeconomic issues related to development, management, resource utilization and resource shortage [2].

For that reason, the level and the limitation of carrying capacity of KILIM Geopark are extremely significant. Universal concern when it comes to carrying capacity is to define how much is too much. A uniform agreement achieved on carrying capacity as affirmed by the previous traditional studies is that '...capacities were reached when users perceived the setting as crowded' [3], meanwhile [4] view carrying capacity as '...the level of use beyond which impacts exceeds levels specified by evaluative standards'. Scholars and other interested personnel have voiced out their concerns on the 
ability of the tourism industry consumers to enjoy their activities without having to jeopardize their tourism experience level. Here, the power of social carrying capacity comes into focus.

\section{Literature Review}

The scholars are traditionally focusing on the environmental and economic aspects, while paying limited attention towards the social aspects when analyzing the tourism carrying capacity issues. Nonetheless, the overlaps '... distinction between social capital and human capital [which is then viewed] as sources rather than consequences' [5], social carrying capacity starts to gain in importance and in popularity. This is captured by Jovicic and Dragin [6] who assert that any usage by tourists shall '...not induce unacceptable and irreversible change in the environmental, social, cultural and economic structure of the destination'. From the perspective of planning, this directly translated into the human population rights to take pleasure in what the surroundings are offering them; however, they should take into account the impact of their actions on the chances of the surroundings being enjoyed by the future generation. While the carrying capacity terminology was said to be first coined by biologists Xizhe et. al. [2], to date, social carrying capacity is yet to have a uniform definition despite its importance in ensuring the achievement of sustainable tourism development. In general, social carrying capacity is the reaction of the local people towards the tourism development of a place, which is positively viewed. Overviewing from the recreational perspective, De Ruyck et. al. [7] come to conclude that perception towards social carrying capacity varies according to demographic, inherited cultural background as well as social background factors.

According to Savariades [4], social carrying capacity is something that relates to the tolerance level in accepting changes that are already exceeding a certain point of acceptance; where this in return, directly influence individuals' tourism experience. Here, it refers to the tourists-host community interaction where the acceptances limit point of host community towards tourists especially and tourism development generally is assumed as the major factor that concedes tourists in seeking new destination. Echoing this, Lawson et. al. [8] examine the tourists-host community interaction by looking at the tourists' attitudes and behaviour when facing delay in service and the host community's management when accommodating the tourists. It is learned that, the tolerance level is higher when tourists experienced a crowded environment compared to when tourists experienced delay in service. Leujak et. al. [9] who view social carrying capacity from the islands perspective emphasize on '...the relationship of tourism with the local society/culture, the effects on local production systems and the economy of the island, quality of life but also the demands and impacts on resources such as water and energy [in addition to] the management of waste'.

Sterl et. al. [10] supports Mexa et. al. [11] statement and in addition, point the significance of including the managerial and past experience aspects in the evaluation framework. While past experience plays a pivotal role in steering the destination preference, the managerial aspect is responsible for buffering the impact of and enhancing the past experience. In cases where the tolerance level that goes beyond the accepted limit, the managerial aspect is to give consideration to relocating and replacing of activities [10]. Similarly, Jovicic and Dragin [6] concur with Mexa et. al. [11] statement while further emphasizing that social carrying capacity should also be viewed from the political and economic perspectives. While previously discussed studies were more toward viewing the social carrying capacity as discomfortness that mostly bears by the host community, Sayre [12] envisages social carrying capacity as the disadvantage feeling felt by the tourists, which resulted from limit points of carrying capacity.

\section{Research Methods}

A self-administered questionnaire survey, which echoes [6] work, was employed as the data collection instrument that gathers information on demographic (age, gender, marital status, education level, occupation and monthly income), travel (information resources, number of visitation, main purpose of visitation and length of stay) and perception (safety, hospitality and tourism facility). Respondents' 
perception towards social carrying capacity was evaluated through 6-point Likert scale statements. Prior to the actual data collection, the data collection instrument was tested for validity and understand-ability where 25 personnel participated in the pilot study. Based on the pilot study findings, minor changes were made to the structure of the statements for better comprehension purpose. Data collection was undertaken within two weeks time frame in March 2014. For the purpose of reliability, data collection is restricted to: visitors with minimum age of 18 , visitors who use private transportation mode, visitors who spend more than 3 hours and visitors who mention KILIM Geopark as their main tourism destination. Of 380 distributed questionnaires, this working paper has successfully retrieved 341 valid and usable questionnaires, of which, the figure amounted to $89.74 \%$ response rate. The social carrying capacity of KILIM Geopark was evaluated using 7 variables (increase in tourist arrival: tourist arrival, high number of tourist has contributed to safety issue: safety issue, a good accessibility to the destination has contributed to a higher tourist involvement in tourism activities: good accessibility to the destination, increase in tourists' arrival has contributed to a decrease in tourism experience: tourism experience, tourists are welcomed by the local community: acceptance by host, increase in tourist' arrival is contributed by similarity/comfortability in identity: similarity in identity, and local and tourists are competing to use the facilities: access to facilities). The evaluation is divided into two phases where while the first phase examines the relationship between variables, the second phase deals with studying the relationship between the key factors and the selected independent variables (age, gender, nationality, education level, occupation and types of visitors).

\section{Research Findings}

The first part of this section presents the preliminary results related to visitation purposes and demographic (Tables 1 and 2) and the second part reveals the findings of social carrying capacity. Table 1 shows a similar pattern of distribution for visitation purposes. From Table 2, it is learned that majority of tourists from all age groups visited KILIM Geopark for holiday/vacation/leisure purpose, followed by business/work purpose. On the other hand, Table 2 indicates the following distribution: female respondents contribute to $55.13 \%$ of total visitors with $56.38 \%$ aged between 18 and 30 , similar age group made up the majority of male tourists population, near normal distribution between Malaysian (49.69\%) and international (50.31\%) visitors with both groups are largely dominated by tourists aged 18 to $30,52.06 \%$ of total visitors are married, almost $40.00 \%$ visitors fitted into the unemployed category, $38.53 \%$ visitors visited KILIM Geopark for the first time and $72.43 \%$ of the total visitors are graduate students.

Table 1: Profile of Visitation Purposes

\begin{tabular}{|c|c|c|c|}
\hline \multirow{2}{*}{ Purposes } & \multicolumn{3}{|c|}{ Age group } \\
\cline { 2 - 4 } & $\mathbf{1 8}$ to 30 & $\mathbf{3 1}$ to 50 & 51 and above \\
\hline Visit friends/relatives & 10 & 3 & 1 \\
\hline Business/work & 14 & 14 & 4 \\
\hline Holiday/vacation/leisure & 149 & 81 & 47 \\
\hline Education & 8 & 4 & 3 \\
\hline
\end{tabular}

It is within this working paper interest to emphasize that the following discussion is derived when looking at the studied variables as a whole. Correlation analysis on relationships between variables present 16 weak strength relationships and 6 medium strengths relationships, with all relationships are significant at 0.01 level (2-tailed). Further observation reveals that only three variables (tourist arrival, safety issue and access to facilities) exhibit significant relationship with all the studied variables, of which, 'access to facilities' variable presented all 6 weak strength relationships. From results, it is learned that both 'safety issue' and 'access to facilities' variables are poorly related to 'acceptance by host' variable. 
Table 2: Profile of Respondents.

\begin{tabular}{|c|c|c|c|}
\hline \multirow[t]{2}{*}{ Attributes } & \multicolumn{3}{|c|}{ Age group } \\
\hline & 18 to 30 & 31 to 50 & 51 and above \\
\hline \multicolumn{4}{|c|}{ Gender } \\
\hline Male & 72 & 45 & 26 \\
\hline Female & 106 & 54 & 28 \\
\hline \multicolumn{4}{|c|}{ Nationality } \\
\hline Malaysian & 108 & 42 & 11 \\
\hline International & 66 & 54 & 43 \\
\hline \multicolumn{4}{|c|}{ Status } \\
\hline Single & 136 & 21 & 6 \\
\hline Married & 45 & 81 & 51 \\
\hline \multicolumn{4}{|c|}{ Occupation } \\
\hline Government staff & 15 & 25 & 11 \\
\hline Private company & 52 & 31 & 6 \\
\hline Self-employed & 22 & 21 & 7 \\
\hline Unemployed & 83 & 15 & 27 \\
\hline \multicolumn{4}{|c|}{ Types of visitors } \\
\hline First time visit & 73 & 37 & 18 \\
\hline Repeat visitors & 97 & 63 & 38 \\
\hline \multicolumn{4}{|c|}{ Education level } \\
\hline Non-formal & 2 & 0 & 0 \\
\hline Primary/secondary & 41 & 30 & 13 \\
\hline Graduate school & 136 & 63 & 27 \\
\hline
\end{tabular}

Regression analysis was done in order to study the variables' contribution in influencing the social carrying capacity (Table 3 ) and which variable(s) offers a crucial change in influencing the level of social carrying capacity (Table 4), from the perspective of two IVs (age and types of visitors). In the first phase of assessment, all models (DV-IV relationship) are positively significant for 'types of visitors', except for 'safety issues' and 'access to facilities' (Table 3). Here, it can be concluded that 'age' relates to the practicality dimension of tourism industry while 'types of visitors' is more toward to the psychological dimension. From Table 3, 'good accessibility to the destination' and 'similarity in identity' contributed the highest influence in social carrying capacity (more than $50.00 \%$ ) while interestingly; 'tourism experience' plays the smallest influence on social carrying capacity. The second phase of assessment involves studying the highest and the lowest influence value of a variable towards a particular variable.

In this phase, DVs were tested against each other while controlling for IVs. From Table 4, it is learned that each variable is uniquely explained by different variable (excluding 'access to facilities' and 'similarity in identity') and despite the variables' moderate strength relationships; it is deemed that each variable plays a pivotal role in influencing other specific variable in terms of determining the social carrying capacity. When studying the linear relationship, it is found that 'similarity in identity' plays a pivotal role in influencing 'good accessibility to the destination' and 'tourist arrival' where the level of influence is controlled by 'acceptance by host'. On the other hand, 'tourism experience' contributes to changes in 'safety issue' where the changes level is manipulate by level of changes in 'access to facilities'. 
Table 3: Results Obtained from Regression Analysis.

\begin{tabular}{|l|l|}
\hline \multicolumn{1}{|c|}{ Variables } & \multicolumn{1}{c|}{ Results } \\
\hline Tourist arrival & $\mathrm{R}^{2}=.470, \mathrm{~F}(6,287)=41.518, p .000$ \\
\hline Safety issue & $\mathrm{R}^{2}=.451, \mathrm{~F}(6,287)=38.466, p .000$ \\
\hline Good accessibility to the destination & $\mathrm{R}^{2}=.565, \mathrm{~F}(6,287)=60.907, p .000$ \\
\hline Tourism experience & $\left.\mathrm{R}^{2}=.383, \mathrm{~F}(6,287)=29.098\right), p .000$ \\
\hline Acceptance by host & $\mathrm{R}^{2}=.405, \mathrm{~F}(6,287)=31.875, p .000$ \\
\hline Similarity in identity & $\mathrm{R}^{2}=.515, \mathrm{~F}(6,287)=49.758, p .000$ \\
\hline Access to facilities & $\mathrm{R}^{2}=.407, \mathrm{~F}(6,287)=32.189, p .000$ \\
\hline
\end{tabular}

Table 4: Results in Relation to the Influence Value

\begin{tabular}{|l|l|}
\hline \multicolumn{1}{|c|}{ Variables } & \multicolumn{1}{c|}{ Highest influence value } \\
\hline Tourist arrival & $\begin{array}{l}\text { Good accessibility to the destination }(b=.426, t(7.014)= \\
p .000)\end{array}$ \\
\hline Good accessibility to the destination & Similarity in identity $(b=.267, t(4.918)=p .000)$ \\
\hline Safety issue & Tourism experience $(b=.231, t(4.230)=p .000)$ \\
\hline Tourism experience & Access to facilities $(b=.304, t(5.234)=p .000)$ \\
\hline Acceptance by host & Similarity in identity $(b=.465, t(7.750)=p .000)$ \\
\hline \multicolumn{1}{|c|}{ Variables } & \multicolumn{1}{c|}{ Lowest influence value } \\
\hline Tourist arrival & Acceptance by host $(b=.129, t(2.315)=p .021)$ \\
\hline Safety issue & Access to facilities $(b=.188, t(3.336)=p .001)$ \\
\hline Good accessibility to the destination & Safety issue $(b=.235, t(4.588)=p .000)$ \\
\hline Tourism experience & Safety issue $(b=.259, t(4.230)=p .000)$ \\
\hline Acceptance by host & Tourist arrival $(b=.145, t(2.315)=p .021)$ \\
\hline Similarity in identity & Tourist arrival $(b=.003, t(0.060)=p .952)$ \\
\hline Access to facilities & Tourist arrival $(b=.158, t(2.536)=p .012)$ \\
\hline
\end{tabular}

Differing from the above mentioned studies documenting the positive impact of demographic factors on social carrying capacity, this working paper observes an interesting finding. Out of 42, this working paper only found six positive relationships. The first relationship was observed between 'age' and 'tourism experience' where at $p .016$, it is learned that $5.1 \%$ of $22.7 \%$ of the total variance was explained. The second relationship was observed between 'gender' and 'safety issue' where at $p .956$, it is found that $0.4 \%$ of $5.9 \%$ of the total variance was explained. The third positive relationship is between 'occupation' and 'tourist arrival' where at $p .043,5.4 \%$ of $23.3 \%$ of the total variance was explained. The fourth positive relationship was observed between 'occupation' and 'good accessibility to the destination' where at $p .034,5.77 \%$ of $27.7 \%$ of the total variance was explained. The fifth positive relationship is between 'education level' and 'tourist arrival' where at $\mathrm{p} .000$, it is learned that $8.6 \%$ of $29.4 \%$ of the total variance was explained. The last positive relationship was observed between 'education level' and 'good accessibility to the destination' where at p .002, 6.7\% of 25.8\% of the total variance was explained.

\section{Discussion and Conclusion}

The results suggest that all variables are considered as few of many other factors that are important in evaluating the social carrying capacity. To this working paper, 'tourism experience' variable should be of interest to the appointed bodies as to date, tourism industry and tourism activity is no longer considered as the rich population dominant due to high dispensable income. In addition, this working 
paper observes different results compared to the previously discussed literature in relation to the effect of demographic factors. Results suggest that the understanding of and the perception towards social carrying capacity are more likely steered by ones awareness and responsibility obligation when undertaking the tourism activities [9]. It is therefore, within this working paper knowledge, in the case of KILIM Geopark, additional attention should be given to plan the pragmatic approach to accommodate the tourists' awareness and responsibility obligation, from the perspective of demand and supply chain.

It is within this working paper interest to bring the attention towards three variables, namely: tourist arrival, safety issue and access to facilities. It is found that 'safety issue' is highly interlinks with the following variables: tourist arrival, access to facilities and tourism experience. In the context of tourist arrival, it is learned that higher influence is contributed by 'safety issue' variable where for example, changes of $1 \%$ made to the 'safety issue' variable will contribute to an additional of $20 \%$ of tourist arrival $(b=.527, t(10.834)=p .000)$. Echoing [4] who argue that 'safety issue' variable should be deal with 'degrees of host irritations [that is] depending on the volume of tourism', this working paper believes that interests shall be diverted to vandalism given the positive relationship between vandalism (tourism and public facilities), safety issue and tourist arrival (here refers to KILIM Geopark tourism image). In cases of 'access to facilities' that is more influenced by 'safety issue', result indicates an additional of $20 \%$ of positive perception towards the idea of tourists and host community competing against each other to use the facilities could be achieved, when $1 \%$ change is made to 'safety issue' variable $(b=.490, t(9.826)=p .000)$. To this working paper, 'access to facilities' can be managed if KILIM Geopark is established as a seasonal tourism spot and this in return, could help in better catering and accommodating different types of visitors.

This working paper comes to conclude that 'tourism experience' is playing an effective role in evaluating the social carrying capacity, given the higher values and the connection to 'access to facilities' and 'safety issue'. An additional of $19 \%$ of positive perception towards an increase in tourism experience is expected when $1 \%$ of change is made for 'safety issue'. Nevertheless, the complex relationship of 'tourism experience' within the evaluation framework shall no longer be traditionally viewed. It is within this working paper interest for 'tourism experience' to be envisaged as something that is gained for free of charge. Yet, the maximum value of it will be enjoyed when ones getting engaged in tourism activity with the understanding of awareness and responsibility are the two factors at hand that created their tourism experience (expectation and satisfaction). Having said that, this working paper strongly emphasizes that tourism experience (expectation and satisfaction) responsibility is no longer solely bear by the host community. Rather, based on the currently existing situation of the tourism world, both tourists and host community play a significantly unique part in ensuring tourists are enable to get hold of the maximum value of tourism experience.

\section{Acknowledgement}

This project was funded through a research grant from the Ministry of Higher Education, Malaysia under the Long-Term Research Grant Scheme 2011 [LRGS Grant No. JPT.S (BPKI)2000/09/01/015Jld.4(67)].

\section{References}

1. Marzuki, A., Mohamad, D. \& Abdullah, S. (2014). Visitors' satisfaction towards geopark attractions. Anatolia: An International Journal of Tourism and Hospitality Research, http://www.tandfonline.com/action/showCitFormats?doi=10.1080/13032917.2013.870916

2. Xizhe, P., Xiuyun, G., \& Xuehui, H. Future prospects for population development in Shanghai. Asian Population Studies 1, 3, 261-281 (2007)

3. Tarrant, M. A., \& English, D. B. K. A crowding-based model of social carrying capacity: applications for whitewater boating use. Journal of Leisure Research 28, 3, 155-168 (1996) 
4. Savariades, A. Establishing the social tourism carrying capacity for the tourist resorts of the east coast of the Republic of Cyprus. Tourism Management 21, 147-156 (2000)

5. Mauerhofer, V. Social capital, capacity and carrying capacity" exploring basics of 'socially sustainable economic degrowth'. Conference proceedings $2^{\text {nd }}$ Conference on Economic Degrowth for Ecological Sustainability and Social Equity, Barcelona (2010)

6. Jovicic, D., \& Dragin, A. The assessment of carrying capacity: a crucial tool for managing tourism effects in tourist destinations. Turizam 12, 4-11 (2008)

7. De Ruyck, M. C., Soares, A. G., \& McLachlan, A. Social carrying capacity as a management tool for sandy beaches. Journal of Coastal Research 13, 3, 822-830 (1997)

8. Lawson, S. R., Manning, R. E., Valliere, W. A, \& Wang, B. Proactive monitoring and adaptive management of social carrying capacity in Arches National Park: an application of computer simulation modelling. Journal of Environmental Management 68, 305-313 (2003)

9. Leujak, W. \& Ormond, R. F. G. Visitor perceptions and the shifting social carrying capacity of South Sinai's Coral Reefs. Environ Manage 39, $472-489$ (2007)

10. Sterl, P., Wagner, S., \& Arnberger, A. (2004). Social carrying capacity of canoeists in Austria's Danube Floodplains $\quad$ National Park. $\quad$ Retrieved from http://www.metla.fi/julkaisut/workingpapers/2004/mwp002.htm

11. Mexa, A., Collovini, A., Parpairis, A., \& Konstandoglou, M. (2001). Defining, measuring and evaluating carrying capacity in European tourism destinations. Retrieved from $\mathrm{http} / / /$ ec.europa.eu/environment/iczm/pdf/tcca_en.pdf

12. Sayre, N. F. The genesis, history and limits of carrying capacity. Annals of the Association of American Geographers 98, 1, 120-134 (2008) 